\title{
Detecting Disordered Eating among Recreational Exercisers; Exploring the Role of Personal Trainers
}

\author{
Hilary J. McDermott, Carolyn Plateau, Leigh Martin \\ School of Sport, Exercise and Health Sciences, National Centre for Sport and Exercise Medicine, Loughborough University, \\ Loughborough, UK \\ Email: H.J.McDermott@lboro.ac.uk
}

How to cite this paper: McDermott, H. J., Plateau, C., \& Martin, L. (2018). Detecting Disordered Eating among Recreational Exercisers; Exploring the Role of Personal Trainers. Psychology, 9, 2824-2836. https://doi.org/10.4236/psych.2018.914162

Received: August 14, 2018

Accepted: December 17, 2018

Published: December 20, 2018

Copyright (c) 2018 by authors and Scientific Research Publishing Inc. This work is licensed under the Creative Commons Attribution International License (CC BY 4.0).

http://creativecommons.org/licenses/by/4.0/

\section{c) (i) Open Access}

\begin{abstract}
This study aimed to understand how personal trainers identify and manage disordered eating among their clients. Semi-structured interviews were undertaken with eleven UK based personal trainers to document their experiences of working with clients exhibiting symptoms of disordered eating. The interviews were recorded, fully transcribed and subjected to a thematic analysis. The findings suggest that personal trainers rely on external cues to identify disordered eating among clients such as changes to physical appearance, exercise behaviours and performance. The findings also revealed that personal trainers lack knowledge and hold misconceptions about disordered eating. Such misconceptions influenced their ability to identify and manage potential problems among their clients. Participants described the need for further education and guidelines to increase their knowledge and confidence in identifying and managing disordered eating among their clients. The findings from this study will be useful for professional bodies and practitioners in the development of guidelines and educational material for personal trainers.
\end{abstract}

\section{Keywords}

Disordered Eating, Personal Trainers, Education, Fitness Industry, Exercise

\section{Introduction}

Disordered eating incorporates a range of problematic eating behaviours, attitudes and body image distortions including restrictive eating; fasting or skipping meals, the use of diet pills, laxatives and diuretics and engaging in binge-eating and/or purging behaviours (Nattiv et al., 2007). It has been associated with a reduced quality of life across social, physical and psychological dimensions (e.g., 
Herpertz-Dahlmann, Wille, Holling, Vloet \& Ravens-Sieberer, 2008; Leung, Ma, \& Russell, 2013).

Exercise attitudes and behaviours are recognised as having an important role in the aetiology and maintenance of disordered eating (Meyer, Taranis, Goodwin, \& Haycraft, 2011). Research suggests that exercising in a rigid or compulsive manner to modify weight and shape or to help cope with negative emotions is closely linked to disturbances in eating behaviour (e.g., Goodwin, Haycraft, \& Meyer, 2012; Plateau et al., 2014). Individuals with disordered eating may seek opportunities within the fitness environment to engage in rigid exercise programmes (Meyer et al., 2011) and seek the support of a personal trainer. Personal trainers are therefore in a prime position to identify symptoms of disordered eating, such as disturbances in eating and compulsive and rigid exercise behaviours (Manley, O'Brien, \& Samuels, 2008). This is important as early identification and treatment of disordered eating is critical in promoting recovery (Lock, Le Grange, Agras, \& Dare, 2001).

Previous research has identified that professional coaches have limited knowledge and confidence when dealing with disordered eating in elite and non-elite athletes (Nowicka, Eli, Ng, Apitzsch, \& Sundgot-Borgen, 2013; Plateau, McDermott, Arcelus, \& Meyer, 2014) whereas knowledge of eating disorders and nutrition is expected and/or assumed among personal trainers (Yager \& O’Dea, 2005). Limited research has been conducted with those working within the recreational exercise industry and that which has been undertaken has revealed difficulties among fitness instructors in identifying eating problems (Manley et al., 2008). It is important to improve our understanding of the challenges faced by personal trainers in identifying and managing disordered eating among their clients.

There are no guidelines in place in the UK for those working in recreational exercise environments with regards to identifying and managing disordered eating (Giordano, 2010). Identifying the areas where fitness professionals in the UK believe that they require additional support is likely to be the first step towards developing educational programmes and resources for personal trainers. To address this gap in knowledge this study therefore aimed to gain an understanding of the experiences of personal trainers working with clients with disordered eating. The specific objectives were to:

- Gain information on how personal trainers identified disordered eating in clients;

- Establish what challenges personal trainers face in identifying disordered eating in clients, and

- Understand what strategies personal trainers employ to manage disordered eating within their clients.

\section{Method}

\subsection{Participants}

A Purposeful sample (Sparkes \& Smith, 2014) of 11 participants (9 male) regis- 
tered with the UK Register of Exercise Professionals (REP), were recruited. At the time of interview all were working as personal trainers in the UK. Six of the participants were employed at fitness centres, whilst the remaining five were self-employed. All participants reported a desire for weight loss as a key reason for clients seeking their services, with nearly all participants $(n=10)$ using weight-monitoring strategies (such as weighing clients or taking body measurements) to track clients' progress. Written informed consent was obtained from all participants prior to the commencement of the interviews.

\subsection{Procedure}

The study was subject to and in compliance with the requirements of Loughborough University's Ethical Advisory Committee for research involving human participants. Semi-structured interviews were employed to explore the experiences of personal trainers working with clients exhibiting symptoms of disordered eating. The interviews were conducted either face-to-face $(n=9)$ or via telephone ( $\mathrm{n}=2)$. Sturges and Hanrahan (2004) demonstrated that the number, nature and depth of responses during interviews do not differ across modality.

Over a period of three months, information about the study was delivered to recreational exercise facilities in the UK known to the researcher. The centres were asked to display the information and interested participants were invited to contact the researcher directly.

An interview schedule was developed (see Table 1) which was informed by the current literature and in consultation with experts in the field. The schedule explored participants' understanding of disordered eating and encouraged participants to describe relevant experiences. All interviews were conducted by the same researcher, trained in interview techniques and lasted between 31 and 75 minutes. The interviews were recorded with the knowledge and consent of participants and subsequently transcribed verbatim.

The researcher was an "insider" researcher (Corbin Dwyer \& Buckle, 2009) in that she was a qualified personal trainer and had good knowledge and understanding of the terminology used by participants. Her experience was likely to enhance acceptance by the participants and assisted the research by facilitating a good rapport with participants (Corbin Dwyer \& Buckle, 2009).

Table 1. Interview schedule.

Section A: Demographic Information

Section B: Training History

At the moment where do you work as a personal trainer? Details?

What is your area of expertise?

\section{Section C: Knowledge of Disordered Eating}

What does the term disordered eating or eating disorders mean to you? Types of eating disorders you are aware of? Do you know any symptoms of these disorders? Who do you think may suffer from them? How common do you think these disorders are? How serious an issue do you think eating disorders are? 


\section{Continued}

\section{Section D: Experience of Clients with Disordered Eating}

Have you ever encountered a client that you think may have been suffering from disordered eating? Has a client ever lost a large amount of weight really quickly that wasn't part of their programme with you? Have any clients been extremely strict about their eating and exercise behaviour to the extent it interfered with everyday life? Do any of your clients exercise over and above what you have prescribed as part of their weekly exercise programme? Are you aware of any of your clients regularly "punishing" themselves after a binge session i.e. after a big weekend or night out?

How did you know your client had issues with their eating? Observation? Disclosure from the client or another gym user?

How confident were you that these signs and symptoms may indicate problematic eating? What was it that made you confident it was/was not disordered eating? Did you find these signs and symptoms worrying? What signs and symptoms would you look out for when identifying disordered eating? Would these be the same for male and female clients? How successful do you feel you have been at identifying disordered eating within clients?

Did you experience any difficulties or barriers in identifying disordered eating? How did you decide it was disordered eating? Did you seek advice from anyone else regarding whether or not your client had disordered eating? Was there anything that helped you to identify the disordered eating or anything that you feel may have been useful to know about/have access to?

Can you recall any particular feelings or emotions you experienced when you suspected your client had disordered eating? What was your initial reaction? How do you feel about it now?

After identifying a suspected disordered eating, what did you do next? Did you approach the client about it? YES-Describe this interaction? How confident did you feel? Was the interaction successful? NO-Why not? What would you have done differently?

\section{Section E: Training and Support Systems}

What, if anything, do you feel has been useful from your training in terms of identifying and/or dealing with this issue? Where did you receive your training? Do you feel you received enough information and guidance on dealing with disordered eating in your initial training? What other training or information do you feel may be beneficial?

At the time, when you identified suspected disordered eating, did you know who or where to go to for support? Who/where did you go? How did you know to take this action? Are these still the same people or places you would go to now?

What support is currently available for you and/or your clients regarding this problem? Is the information clear? Have you sought any support? Tell me about your experience of using this service? What other mechanisms or guidance do you feel would be beneficial?

What support and guidance would you like to receive? How do you think this service should be delivered? How could it be made accessible to clients as well as trainers?

As a personal trainer, what do you think your responsibility is with regards to identifying and managing disordered eating among your clients? How much responsibility lies with you? Do you feel equipped to handle this responsibility? Is there anyone that should share this responsibility with you?

What is your opinion on there being set guidelines for personal trainers regarding the identification and management of disordered eating among clients? Would you find guidelines useful? What information would you like to see included in these guidelines? Do you think guidelines could have helped you when dealing with the experience you discussed earlier?

Thank you for taking part in this interview. 


\subsection{Data Analysis}

The transcribed material from the interviews was analysed using Thematic Analysis as described by Braun and Clarke (2006). A deductive approach was initially used to identify themes associated with the research questions while inductive analysis allowed for novel and unexpected themes to emerge from the data (Guest, MacQueen, \& Namey, 2012).

Multiple readings were undertaken to facilitate familiarisation with the data. To aid analysis, notes were made on initial points of interest while referring to the transcript. The analysis progressed to generating initial codes on a case by case basis which were organised into potential themes which were reviewed and revised. As new information emerged, new themes were created and incorporated into the thematic structure. Validation of the coding was achieved through review of the coding by another experienced researcher independent to the research. The two researchers independently coded a sample of the data and during subsequent discussions alternative interpretations were explored to ensure a robust analysis.

\section{Results}

The codes were grouped under three overriding themes relating to the research questions: 1) Identification of disordered eating in clients; 2) Challenges to identification; and 3) Management of disordered eating.

\subsection{Identification of Disordered Eating in Clients}

Participants reported a range of signs and symptoms which they believed indicated disordered eating in a client. These included changes to physical appearance, reduced exercise performance and ability, changes in exercise attitudes behaviours, and inadequate food and eating habits as reported in a food diary (see Table 2).

The majority of participants reported that they monitored client's weight to track their progress towards weight goals, however this was not utilised to identify disordered eating. Instead, participants relied on observed changes to physical appearance to detect disordered eating among their clients, such as a loss of muscle, thinness, and looking unwell. A 30-year-old male trainer described how he believed that rapid changes in body appearance were a key indicator of disordered eating:

"Obviously, if someone's body appearance changes rapidly, I think some people start to take on an almost unhealthy look when they have lost too much weight too quickly [...] especially if it happens quickly and you see that person on a regular basis then you know it is happening too fast".

Food diaries were often used to detect poor eating patterns, a lack of nutritional knowledge and potential disordered eating behaviours. In several cases the food diary facilitated discussions between the trainer and client about nutrition. A 31-year-old male trainer described identifying disordered eating from client's food diaries: 
Table 2. Theme 1: Identification of disordered eating in clients.

\begin{tabular}{cc}
\hline Subtheme & Code \\
\hline Changes to physical appearance & Thin appearance \\
& Observed loss of muscle \\
Gaunt appearance & Observed low body fat \\
Food Diary & Food frequency \\
& Nutritional choices \\
& Topic of discussion \\
Exercise Behaviours & Decreasing performance \\
& Excessive exercise \\
Change in Mood & Rigid exercise behaviours \\
& Irritability \\
Responsibility & Depression \\
& Duty of care \\
& Employer responsibility \\
& Legal versus voluntary obligation
\end{tabular}

"I always get someone to do a food diary so I can see what they are eating at the start and I will kind of get them to keep doing that. The first time I saw it, she [ the client] hardly was eating anything, and I was like 'Why are you not eating?' and she was like 'Well cause I am trying to lose weight'. She literally ate breakfast and that was it'.

Changes in exercise regimes and performance were also described as potential indicators, with several participants identifying compulsive and rigid exercise behaviours as indicative of an unhealthy relationship with food. A 31-year-old male trainer described clients feeling faint and struggling with the exercise prescribed:

"They were tired, they were lethargic, not interested ... sometimes you are pushing them hard and they are getting faint, and that can happen, but it will more than likely happen when they haven't eaten enough".

It is interesting that participants conceptualised disordered eating as "not eating enough" and largely overlooked other elements of disordered eating such as bingeing or purging behaviours. In fact, participants largely overlooked the psychological aspect of disordered eating with only two participants demonstrating an awareness of psychological symptoms, such as emotional instability and low mood. Nearly all participants reported that they felt they had a "responsibility" for identifying disordered eating in their clients despite not having a legal duty of care. A 31-year-old male trainer stated:

"Legally I have got no responsibility to safeguard them, but it is up to the individual personal trainer".

Participants therefore demonstrated a moral approach to the identification of disordered eating within their client as opposed to this being driven by legislation. A moral responsibility is likely to vary from trainer to trainer. 


\subsection{Challenges to Identification}

All participants reported difficulties in identifying disordered eating within their clients. Challenges included a poor trainer-client relationship, the hidden and secretive nature of disordered eating and a lack of knowledge and/or confidence about identifying potential eating issues (see Table 3).

Several trainers highlighted that a lack of communication and limited contact time with clients meant it was difficult for them to identify potential eating problems as many associated behaviours were practiced outside of the gym environment. A 24-year-old female trainer described:

"I don't see them enough to identify [disordered eating]. Even if I was training them three times a week that is still not enough to see it, to see the symptoms and signs of it."

The trainers also suggested that the secretive nature of disordered eating meant that some clients would mask signs and symptoms making them difficult to detect. Several trainers reported that clients wore baggy clothes to mask their appearance or were untruthful about their eating and exercise behaviours. A 30-year-old male trainer explained:

"You wouldn't see it as much as they would maybe try and hide it in terms of food, trying to keep quiet what their eating habits are like... That is the hard thing about it, you don't know what is going on. They might say I eat that and I eat that, but they might not".

Trainers reported that inaccurate reporting of food intake by clients made it difficult for them to use food diaries as a reliable means of identifying disordered eating. Participants also reported concerns over their lack of knowledge about disordered eating and several misconceptions about the nature and presentation of disordered eating were evident. For example, several trainers conceptualised the issue as a "female-only" problem, emphasised thinness as a key symptom, and suggested that disordered eating was a result of appearance related concerns. Again this reflects a lack of understanding about the psychological aspects of disordered eating. A small number of trainers also confused disordered eating with nutritionally unbalanced diets, a 31-year-old trainer stated:

"Like people who live off [brand] frozen meals, I would say that is disordered eating I would think, because it is not the right kind of macros nutrients and micro nutrients, but they weren't getting adequate nutrition from it'.

Finally, participants highlighted a lack of confidence in their own knowledge about disordered eating as a key obstacle to identifying potential issues. Some participants expressed concerns over misinterpreting the symptoms and potentially causing offence to clients, whilst one 24-year-old female trainer suggested that she did not have sufficient experience to successfully identify clients with disordered eating:

"But just like any industry, any career, you can't come in at the start and be able to handle everything, that is where experience comes in. If you are in your early twenties, there is no way you are going to consistently be able to identify somebody with an eating disorder, I don't think' 


\subsection{Management of Disordered Eating}

Participants reported some confusion with regards to where the responsibility for management of disordered eating lay. Some participants reported that it was their responsibility to address disordered eating directly with a client, whilst others suggested that it was the role of an employer, a health professional or the individual client to address the issue (see Table 4).

Three trainers expressed concerns over their lack of knowledge and qualifications to manage the situation and reported that the management of disordered eating was outside their scope of practice. A 20-year-old female trainer provided an example:

Table 3. Theme 2: Challenges to identification.

\begin{tabular}{|c|c|}
\hline Sub theme & Code \\
\hline Trainer-client relationship & $\begin{array}{c}\text { Poor quality relationship } \\
\text { Limited frequency of contact } \\
\text { Communication }\end{array}$ \\
\hline Hidden and secretive nature of disordered eating & $\begin{array}{c}\text { Masking behaviours } \\
\text { Clothing } \\
\text { Taboo topic } \\
\text { Lack of honesty }\end{array}$ \\
\hline Misconceptions around disordered eating & $\begin{array}{l}\text { Female-only problem } \\
\text { Thinness concomitant with disordered eating } \\
\text { Centrality of appearance related concerns } \\
\text { Poor nutrition as a result of lack of knowledge }\end{array}$ \\
\hline Confidence & $\begin{array}{c}\text { Lack of experience } \\
\text { Lack of education or resources } \\
\text { Availability of support }\end{array}$ \\
\hline
\end{tabular}

Table 4. Theme 3: Management of disordered eating.

\begin{tabular}{cc}
\hline Sub theme & Code \\
\hline Responsibility & Lack of knowledge or qualification \\
Employer or manager's role & Health professional \\
Client responsibility to take action & \\
Approach client and express concerns \\
Signposting to sources of support \\
Nutrition education \\
Management strategies \\
\\
Reduction in exercise plan \\
Avoidance (fear of exacerbation/upsetting client) \\
Support from colleagues \\
Limited influence \\
Lack of acceptance by client \\
\\
Frequency of contact with client \\
\\
Availability in exercise environment \\
Specific to personal trainers \\
Protection for trainers \\
Education and workshops
\end{tabular}


"I would feel way out of my depth to be managing it [disordered eating]. I sort of would know that from the word go so I wouldn't attempt to".

Different experiences and perspectives on how to approach and manage the issue were also reported by participants. Key strategies in the management of disordered eating focused around communication with the client and nutritional education which were easier to implement where there was a good relationship with the clients. For example, over half of participants reported educating clients on potential benefits of healthy eating and exercise behaviours and encouraging them to adopt these behaviours. A 31-year-old male personal trainer stated:

"It was, I won't say nagging but it was more I was consciously trying to help her out and make her realise you do need to eat and food isn't an enemy it is an energy source at the end of the day and if you eat right then you can do great things."

The management strategies adopted by the participants reflected the idea of disordered eating being a nutritional issue as opposed to a psychological condition. As such, trainers did not pay attention to potential underlying psychological causes such as emotional distress and body dissatisfaction. Participants who reported previous experience of a client with disordered eating stated that they felt more knowledgeable about the condition and were more confident in dealing with subsequent cases. However, several participants reported concerns over making the situation worse or upsetting the client and tended to avoid offering advice. A 33-year-old male trainer gave the impression that he lacked confidence in the management of disordered eating:

"I don't go near it, I distance myself from it unless somebody had come to me. I am like I don't know how to deal with that, I don't want to put you in any more danger, I don't want to get you worse".

Nearly half of the trainers expressed concerns that the advice and support that they offered would not be effective due to a perceived lack of influence over their clients. A 30-year-old male trainer explained the difficulties encountered when trying to advise clients who did not want their help:

"The problem is they can tell you 'oh yeah, yeah, I know! I agree' ... but they can be thinking I will just tell this guy because I want him away from me and I will do my thing".

Finally, all of the participants expressed a need for specific guidelines to aid their identification and management of disordered eating and reported that this would increase their confidence in dealing with this issue. Participants expressed a need for additional resources and educational opportunities to be provided by their employer or professional body. A 30-year-old male trainer suggested that guidelines could offer an important safety net for trainers in negotiating ethical and legal issues:

"But it would be good if there was a set structure to follow, it would keep you right as well [...] don't want to over step the mark so to speak and get yourself into trouble 'cause someone could easily turn round and say I didn't want help in the first place, this person has been harassing me". 


\section{Discussion}

Personal trainers reported employing a number of active strategies to identify disordered eating in their clients, with the majority looking for signs and symptoms such as inadequate nutritional intake and changes in exercise behaviours and performance. However, it was evident that trainers conceptualised disordered eating as characterised by thinness, poor nutritional habits and knowledge and appearance related concerns, and as a condition which only affects females. These beliefs are reflective of some of the "taken for granted" truths about disordered eating, which are pervasive in public and media discourses (Busanich \& McGannon, 2010) and could be tackled through more formal education and guidance for trainers.

The majority of the trainers recognised the impact of low food intake on exercise performance. Many also identified symptoms of compulsive exercise such as rigid exercise and exercising over and above their prescribed schedule (Meyer et al., 2011) which is in contrast to previous research (Bratland-Sanda \& Sundgot-Borgen, 2015). Strategies for managing compulsive exercise were limited, with trainers focusing primarily on improving nutritional knowledge among clients. Providing information about healthy eating may help to resolve a nutritional issue; however, it will be less effective in resolving disordered eating patterns that are related to body image concerns or emotional instability (e.g., Becker, Frank, Nussbaum, \& Herzog, 2004; Stice, Shaw, Burton, \& Wade, 2006). Individuals may require further psychological intervention to support long term change to their eating and exercise cognitions and behaviours (e.g., Yager \& O’Dea, 2008).

Many of the trainers acknowledged a duty of care towards clients, however few felt suitably equipped or confident to deal with disordered eating; a finding which is in line with other research in the area (e.g. Bratland-Sanda \& Sundgot-Borgen, 2015; Manley et al., 2008; Plateau, Arcelus, McDermott, \& Meyer, 2015). Trainers reported requiring additional support from their employers and the professional body to facilitate their involvement in supporting clients and all of the trainers in this study welcomed the provision of guidelines. At present, disordered eating is not part of the curriculum for personal training courses in the UK and few trainers reported having received any information on the issue.

Some trainers described feeling unable to manage disordered eating in their clients. Personal trainers are in an ideal position to identify the early signs of eating problems among recreational exercisers and to prevent an escalation of symptoms (Lock et al., 2001). However, previous research has demonstrated that a lack of knowledge and confidence can prevent frontline individuals from taking action when disordered eating is identified (e.g., Vaughan et al., 2004; Plateau et al., 2015). The findings from this study suggest a need to address the support provided to personal trainers to allow them to capitalise on their position to protect the health and wellbeing of those in recreational exercise contexts. Importantly, educational interventions have been demonstrated to be successful in improving knowledge and confidence around identification in other 
frontline groups (e.g., coaches; Martinsen, Sherman, Thompson, \& Sundgot-Borgen, 2015).

Clarity and guidance around the ethical and legal issues of exercise participation by individuals with disordered eating is also required. Several trainers expressed concerns about exacerbating the condition when challenging clients about their eating and exercise habits; a finding which is in line with other research (Manley et al., 2008). Guidelines and policies on this do not currently exist within the UK, but have been implemented elsewhere (Marks \& Harding, 2004).

It is important to acknowledge the limitations of this study. The range of experience and expertise of participants was diverse; however, this was perceived to contribute to the richness of the data. The gender imbalance in sampling is representative of the gender ratio within the industry (National Register of Personal Trainers UK, 2018). It is acknowledged that since participants were self-selecting, those that responded may have a specific interest in disordered eating or be more active in seeking further training to advance their knowledge in this area. It is recognised the researcher's knowledge and experience as an insider researcher (Corbin Dwyer \& Buckle, 2009) will have shaped the analysis. However, the researcher remained conscious of this potential for bias and reflected on the analysis at key stages, and additional insight was obtained from researchers independent of the study.

This study investigated an overlooked and under researched area with regards to personal trainer's knowledge and experience of disordered eating in their clients. Personal trainers are often frontline staff within commercial recreation centers and are therefore in an ideal position to identify early signs and symptoms of disordered eating. The findings reported here can inform the development of guidance and further training to support them in fulfilling this important role.

\section{Acknowledgements}

This activity was conducted under the auspices of the National Centre for Sport and Exercise Medicine (NCSEM) England, a collaboration between several universities, NHS trusts and sporting and public bodies. The views expressed are those of the authors and not necessarily those of NCSEM England or the partners involved.

\section{Conflicts of Interest}

The authors declare no conflicts of interest regarding the publication of this paper.

\section{References}

(2018). National Register of Personal Trainers' Information on Personal Trainers in UK Towns. http://www.nrpt.co.uk/town/index.htm 
Becker, A. E., Franko, D. L., Nussbaum, K., \& Herzog, D. B. (2004). Secondary Prevention for Eating Disorders: The Impact of Education, Screening and Referral in a College Based Screening Program. International Journal of Eating Disorders, 36, 157-162. https://doi.org/10.1002/eat.20023

Bratland-Sanda, S., \& Sundgot-Borgen, J. (2015). "I'm Concerned-What Do I Do?" Recognition and Management of Disordered Eating in Fitness Center Settings. International Journal of Eating Disorders, 48, 415-423. https://doi.org/10.1002/eat.22297

Braun, V., \& Clarke, V. (2006). Using Thematic Analysis in Psychology. Qualitative Research in Psychology, 3, 77-101. https://doi.org/10.1191/1478088706qp063oa

Busanich, R., \& McGannon, K. R. (2010). Deconstructing Disordered Eating: A Feminist Psychological Approach to the Body, Food and Exercise Relationship in Female Athletes. Quest, 62, 385-405. https://doi.org/10.1080/00336297.2010.10483656

Corbin Dwyer, S., \& Buckle, J. L. (2009). The Space between: On Being an Insider Outsider in Qualitative Research. International Journal of Qualitative Methods, 8, 54-63. https://doi.org/10.1177/160940690900800105

Giordano, S. (2010). Exercise and Eating Disorders: An Ethical and Legal Analysis. New York: Routledge. https://doi.org/10.4324/9780203885543

Goodwin, H., Haycraft, E., \& Meyer, C. (2012). The Relationship between Compulsive Exercise and Emotion Regulation in Adolescents. British Journal of Health Psychology, 17, 699-710. https://doi.org/10.1111/j.2044-8287.2012.02066.x

Guest, G., MacQueen, K. M., \& Namey, E. E. (2012). Applied Thematic Analysis. London: Sage. https://doi.org/10.4135/9781483384436

Herpertz-Dahlmann, B., Wille, N., Holling, H., Vloet, T. D., \& Ravens-Sieberer, U. (2008). Disordered Eating Behaviour and Attitudes, Associated Psychopathology and Health-Related Quality of Life: Results of the BELLA Study. European Child \& Adolescent Psychiatry, S1, 82-91. https://doi.org/10.1007/s00787-008-1009-9

Leung, S. F., Ma, J. L. C., \& Russell, J. (2013). Enhancing Quality of Life in People with Disordered Eating Using an Online Self-Help Programme. Journal of Eating Disorders, 1. https://doi.org/10.1186/2050-2974-1-9

Lock, J., Le Grange, D., Agras, W. S., \& Dare, C. (2001). Treatment Manual for Anorexia Nervosa. A Family-Based Approach. New York: The Guilford Press.

Manley, R. S., O’Brien, K. M., \& Samuels, S. (2008). Fitness Instructors' Recognition of Eating Disorders and Attendant Ethical/Liability Issues. Eating Disorders, 16, 103-116. https://doi.org/10.1080/10640260801887162

Marks, P. \& Harding, M. (2004). Fitness Australia Guidelines: Identifying and Managing Members with Eating Disorders and/or Problems with Excessive Exercise. Sydney: Fitness Australia.

Martinsen, M., Sherman, R. T., Thompson, R. A, \& Sundgot-Borgen, J. (2015). Coaches' Knowledge and Management of Eating Disorders: A Randomised Controlled Trial. Medicine \& Science in Sport and Exercise, 47, 1070-1078. https://doi.org/10.1249/MSS.0000000000000489

Meyer, C., Taranis, L., Goodwin, H., \& Haycraft, E. (2011). Compulsive Exercise and Eating Disorders. European Eating Disorders Review, 19, 174-189. https://doi.org/10.1002/erv.1122

Nattiv, A., Loucks, A. B., Manore, M. M., Sanborn, C. F., Sundgot-Borgen, J., \& Warren, M. P. (2007). American College of Sports Medicine Position Stand: The Female Athlete Triad. Medicine \& Science in Sport and Exercise, 39, 1867-1882.

https://doi.org/10.1249/mss.0b013e318149f111 
Nowicka, P., Eli, K., Ng, J., Apitzsch, E., \& Sundgot-Borgen, J. (2013). Moving from Knowledge to Action: A Qualitative Study of Elite Coaches' Capacity for Early Intervention in Cases of Eating Disorders. International Journal of Sport Science \& Coaching, 8, 343-355. https://doi.org/10.1260/1747-9541.8.2.343

Plateau, C. R., Arcelus, J., McDermott, H. J., \& Meyer, C. (2015). Responses of Track and Field Coaches to Athletes with Eating Problems. Scandinavian Journal of Medicine \& Science in Sports, 25, e240-e250. https://doi.org/10.1111/sms.12286

Plateau, C. R., McDermott, H. J., Arcelus, J., \& Meyer, C. (2014). Identifying and Preventing Disordered Eating among Athletes: Perceptions of Track and Field Coaches. Psychology of Sport \& Exercise, 15, 721-728. https://doi.org/10.1016/j.psychsport.2013.11.004

Plateau, C. R., Shanmugam, V., Duckham, R. L., Goodwin, H., Jowett, S., Brooke-Wavell, K. S. F., Arcelus, J., \& Meyer, C. (2014). Use of the Compulsive Exercise Test with Athletes: Norms and Links with Eating Psychopathology. Journal of Applied Sport Psychology, 26, 287-301. https://doi.org/10.1080/10413200.2013.867911

Sparkes, A. C., \& Smith, B. (2014). Qualitative Research Methods in Sport, Exercise and Health: From Process to Product. Abingdon, VA: Routledge.

Stice, E., Shaw, H., Burton, E., \& Wade, E. (2006). Dissonance and Healthy Weight Eating Disorder Prevention Programs: A Randomized Efficacy Trial. Journal of Consulting \& Clinical Psychology, 74, 263-275. https://doi.org/10.1037/0022-006X.74.2.263

Sturges, J. E., \& Hanrahan, K. J. (2004). Comparing Telephone and Face-to-Face Qualitative Interviewing: A Research Note. Qualitative Research, 4, 107-118.

https://doi.org/10.1177/1468794104041110

Vaughan, J. L., King, K. A., \& Cottrell, R. R. (2004).Collegiate Athletic Trainers' Confidence in Helping Female Athletes with Eating Disorders. Journal of Athletic Training, 39, 71-79.

Yager, Z., \& O’Dea, J. (2005). The Role of Teachers and Other Educators in the Prevention of Eating Disorders and Child Obesity: What Are the Issues? Eating Disorders: The Journal of Treatment \& Prevention, 13, 261-278. https://doi.org/10.1080/10640260590932878

Yager, Z., \& O’Dea, J. (2008). Prevention Programs for Body Image and Eating Disorders on University Campuses: A Review of Large, Controlled Interventions. Health Promotion International, 23, 173-189. https://doi.org/10.1093/heapro/dan004 